\title{
Training Facilitators for Face-to-Face Electronic Meetings: An Experiential Learning Approach
}

\author{
Pak Yoong \\ Victoria University of Wellington, New Zealand \\ Pak.Yoong@vuw.ac.nz
}

\begin{abstract}
The need for effective facilitation in Group Support Systems (GSS) environments is well documented. Results from recent studies of facilitation in face-to-face electronic meetings have demonstrated that more and different research is required before we have a clearer picture of GSS facilitation. The training of GSS facilitators has been acknowledged as an important issue in GSS research but, up to now, has received little research attention. This paper describes an experiential learning approach to the training of facilitators for face-to-face electronic meetings. It begins with a description of the nature of GSS facilitation training. The experiential learning method of training is then explained. Finally, the GSS facilitation training program is described.
\end{abstract}

Keywords: GSS facilitation training, experiential learning, IS education

\section{Introduction}

Early Group Support Systems (GSS) research recognised meeting facilitation skills as a key success factor in electronic meetings (Bostrom et al., 1991 and Vogel et al., 1987). Experimental studies on the effectiveness of human facilitators in electronic environments has produced mixed results (for example, Anson, 1990 and George et al., 1992). This is because the predefined, scripted facilitation approach used in experimental studies does not provide a realistic picture of the active facilitation that occurs in practice and therefore field-based studies that focus on active facilitation are required (Anson et al., 1995).

The literature from field-based studies depicts the GSS facilitation process as both complex and dynamic (Bostrom et al., 1993; Beranek et al., 1993; Clawson, 1992; and Iacono et al., 1990). The facilitators have to consider, among other things, the interplay between computer and human interactions (Iacono et al., 1990), between task and socio-emotional issues (Kelly and Bostrom, 1995), and between routine and flexible activities (Anson, 1990 and Clawson, 1992).

This paper begins with a description of the nature of GSS facilitation training. The second section explains the nature of experiential learning and the GSS facilitation training program used in a research project in which fifteen facilitators, already experienced in conventional meetings, were trained to become

facilitators of electronic meetings. The final section identifies implications for future research.

Material published as part of this journal, either on-line or in print, is copyrighted by the publisher of Informing Science. Permission to make digital or paper copy of part or all of these works for personal or classroom use is granted without fee provided that the copies are not made or distributed for profit or commercial advantage AND that copies 1) bear this notice in full and 2) give the full citation on the first page. It is permissible to abstract these works so long as credit is given. To copy in all other cases or to republish or to post on a server or to redistribute to lists requires specific permission and payment of a fee. Contact

Editor@gise.org to request redistribution permission.

\section{The Nature of GSS Facilitation Training}

The training of GSS facilitators has been acknowledged as an important issue in GSS research (McGoff and Ambrose, 1991; Anson, 1990; Clawson, 1992; Bostrom et al., 1993; Beranek et al., 1993) but, up to now, has received little research attention. Vogel et al. (1987) alluded to this issue as early as 1987 when they commented that "while group skills are recognised as important, little systematic attention has been given to group facilitator training..." (p. 127).

Clawson (1992) set an agenda for research into GSS facilitation training when she identified the following research questions:

* How do we develop facilitative behaviours?

* How do we train people to facilitate effective computersupported interactions?

* How do we appropriately train facilitators to make the transition between traditional and electronic contexts?

* How do we successfully integrate group technology into the facilitators' tool kit? (p. 189).

Anson (1990) advocates that future research in GSS facilitation training should concentrate on identifying the skills and knowledge of GSS facilitation and "the issue of training group members and leaders to facilitate the groups in which they are also involved ... given the cost of involving third-party facilitators" (p. 186). He also suggests (citing Hirokawa and Gouran, 1989) that facilitators should be trained in the general models of process intervention which they can flexibly and adaptively apply.

Bostrom et al. (1991) describe their approach to GSS facilitation training. The training program emphasises the skill of outcome development as "absolutely essential for effective facilitation, especially in electronic environments" (p. 8). Allied to this is the need to develop skills in improving critical meeting interactions and 
GSS facilitation training

teaching people to think differently about the meeting process. Therefore, their training program provides a focus on three major dimensions of the facilitator's role:

(a) developing a process structure (i.e. the agenda) to achieve the meeting's outcome(s),

(b) providing group interaction support that makes the meeting's outcome(s) easier to achieve, and

(c) developing and maintaining relationships among group members.

In terms of the actual GSS product training, their basic assumption is that groupware technology and technical skills are a necessary yet not a sufficient condition for running successful meetings, and therefore the "product training is designed to accomplish three critical learning outcomes: (1) convey the basic logic of the product's operation, tools and interface; (2) build comfort and confidence with the technology; and (3) develop the trainee's ability to map concrete tasks, methodologies and experiences to the product's capabilities" (pp. 18-19).

Ventana Corporation's GSS facilitation training program is offered on four progressive levels: core skills, facilitation, processes and techniques, and certification. The company's latest issue of the publication, GroupSystems@Work (Ventana, 1996), provides information of how entry to each level depends on prior facilitation experience and the completion of a previous level training course. For example, entry to the facilitation level requires the following prerequisite: experience leading meetings, understanding of group dynamics, and must have attended the fundamental core skills course (which is an introduction to the GroupSystems package). The GroupSystems groupware package includes a comprehensive users' manual and a self-paced tutorial.

Numerous researchers have raised the issue of 'how' GSS facilitation training should be conducted (Anson, 1990; Bostrom et al., 1991; Clawson, 1992; Beranek et al., 1993; Yoong, 1995). For example, Anson (1990) advocates that novices should concentrate first on learning to facilitate in the conventional meetings before adding the technology component. However, he recommends that if individuals were selected on their prior facilitation experience then training in the technology first (or concurrent with group dynamics training) would be equally effective. Beranek et al. (1993) propose that observation and apprenticeship should probably be part of a GSS facilitation training program. The existing literature, which focuses on descriptions of the structure and methods of specific training programs, provides an idea of how training is conducted in these situations. Many training programs used a hands-on 'experiential learning' approach with role-modeling, role-playing, simulating real live meetings (mini-meetings), video-taping and feedback, and group discussions. In most instances, the training programs are targeted at participants with at least some prior generic facilitation experience.

\section{Experiential Learning and GSS Facilita- tion Training}

Kolb's (1984) model of experiential learning suggests that learning is a dialectic and cyclical process consisting of four action and reflection stages as shown in Figure 1 and briefly described in Table 1:

Table 1. Kolb's Model of Experiential Learning

\begin{tabular}{|l|l|}
\hline $\begin{array}{l}\text { Concrete } \\
\text { experience }\end{array}$ & $\begin{array}{l}\text { The learners involve themselves } \\
\text { fully and openly in a new experience }\end{array}$ \\
\hline $\begin{array}{l}\text { Reflective } \\
\text { observation }\end{array}$ & $\begin{array}{l}\text { The learners reflect on and observe } \\
\text { the experience }\end{array}$ \\
\hline $\begin{array}{l}\text { Abstract } \\
\text { conceptualisation }\end{array}$ & $\begin{array}{l}\text { The learners create concepts that } \\
\text { integrate the observations into con- } \\
\text { textually relevant models }\end{array}$ \\
\hline $\begin{array}{l}\text { Active } \\
\text { experimentation }\end{array}$ & $\begin{array}{l}\text { The learners use these models for } \\
\text { decision-making and problem- } \\
\text { solving in unfamiliar situations }\end{array}$ \\
\hline
\end{tabular}

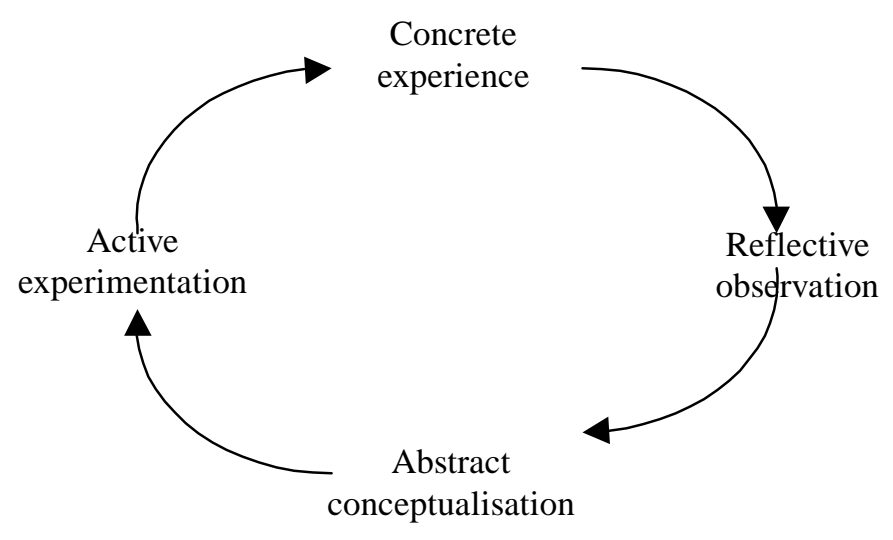

Figure 1. Kolb's Model of Experiential Learning

In practice, this cycle of action and reflection activity does not flow in a linear and sequential fashion. It is far more fluid and dynamic and the learners move back and forth among the stages. The experiential learning model provides a useful guide to learning and progress through the process.

Boud (1993) describes experiential learning as follows:

We must also engage the actual experience of learners so that they can make connections and identify between what they already know and what they are learning ... The learners will have to make the connections for themselves, but we must make our contributions ... in 
ways that assist them ... This typically will involve putting information in context, making initial access very concrete, portraying knowledge in a human context as part of the understanding needed to deal with the real situations rather than abstract ones, and making access to different forms and modes of expression of the ideas. It involves gaining information about students' perspectives and present understanding and misunderstanding. Most importantly it involves equipping students with the tools and developing the skills for them to monitor their own learning and to act proactively rather then reactively (pp. 36-37).

In many respects, Boud's description of experiential learning appeals in that learning to be a facilitator of electronic meetings requires more than just 'reading', 'talking' and 'thinking' about it. It also requires the actual experience of 'doing' it. The combined efforts of action and reflection provide the essential processes for enabling facilitators to gain the skills and insights for managing and supporting those parts of an electronic meeting which are uncertain and unpredictable. Facilitators need to know what they can or cannot do before embarking on improving or changing these facilitation behaviours. This link between what is already known - the facilitators' experience in conventional meetings - and what they want to know, change or improve - the use of the electronic meeting tools - is also a common feature of experiential learning.

Some of Boud's principles for guiding and informing experiential learning are useful for GSS facilitation training:

* Experience is the foundation of and stimulus for learning

* The effects of prior experience influence all learning

* Learners actively construct their own experience

* Learning is a holistic process which has affective, cognitive and connotative features

* Learning is socially and culturally constructed

* Learning occurs in a socio-emotional context

(A fuller description of these principles will be given in a later section).

The next section describes the nature of a GSS facilitation training program and its relationship with some principles of experiential learning as advocated by Boud (1993).
Table 2: The Components of a GSS Facilitation Training Programme: Planning and Supporting Electronic Meetings

\begin{tabular}{|l|l|l|}
\hline $\begin{array}{l}\text { Module } \\
\text { Number }\end{array}$ & $\begin{array}{l}\text { Title of } \\
\text { Module }\end{array}$ & $\begin{array}{l}\text { Brief Description of the Mod- } \\
\text { ule }\end{array}$ \\
\hline 1 & $\begin{array}{l}\text { The Tools of } \\
\text { an Electronic } \\
\text { Meetings }\end{array}$ & $\begin{array}{l}\text { This module provides the neces- } \\
\text { sary hands-on skills and } \\
\text { knowledge of the GSS product } \\
\text { (GroupSystems V or Vision- } \\
\text { Quest). }\end{array}$ \\
\hline 2 & $\begin{array}{l}\text { Planning and } \\
\text { Managing an } \\
\text { Electronic }\end{array}$ & $\begin{array}{l}\text { This module focuses on (a) how } \\
\text { to plan and design an agenda for } \\
\text { an electronic meeting, (b) how to } \\
\text { balance human and computer } \\
\text { interactions, and (c) the role of } \\
\text { the facilitators in electronic } \\
\text { meetings. }\end{array}$ \\
\hline 3 & $\begin{array}{l}\text { Putting It All } \\
\text { Together }\end{array}$ & $\begin{array}{l}\text { This practical module provides } \\
\text { opportunities for trainees to plan } \\
\text { and facilitate 'live' electronic } \\
\text { meetings. }\end{array}$ \\
\hline
\end{tabular}

\section{A GSS Facilitation Training Programme}

Between March 1993 and June 1994, as a partial requirement for a doctoral research study, three groups of five experienced meeting facilitators participated in a GSS facilitation training program. The training program consists of three modules as shown in Table 2.

The trainee facilitators (trainees) studied Modules 1 and 2 during the two full-day and two half-day sessions. The practical component, 'Putting It All Together', took place soon after the training. The trainees were expected to demonstrate the skills and knowledge acquired from the preceding training program. They did this by planning, managing and facilitating a 'live' electronic meeting which lasted about three hours. All the meetings were videotaped and the recordings used for giving feedback to the trainees and as research data for this study.

\section{A Typical Training Session}

Experiential learning method encourages changes to a training session's agenda to accommodate the trainees' needs as they emerged during the session. For example, if the trainees thought that more time should be spent on familiarising themselves with the GSS tools, then the agenda was changed to do just that. However, most training sessions followed this agenda:

- $\quad$ Settling in - At the beginning of each session, all trainees were encouraged to talk about what was going on in their professional, personal and family lives. Boud (1993) advocates that adult learning is a holistic process, which has affective and cognitive features. We found that these settling-in periods allowed the trainee and peer trainees to be aware of what each was thinking and feeling. For example, during one training program, two of the trainees were feel- 
ing stressed because impending changes at work threatened them with job redundancy. Exchanging this sort of information and their response to it resulted in increased trust among the trainees. We have used such events to learn from and have examined the implications these may have for the facilitation of 'live' meetings. For example, knowledge of how some participants are feeling at the beginning of a meeting can become useful contextual cues for interpreting their behaviour during meetings.

- $\quad$ Learning the GSS tools: The learning of each GSS tool was structured as described by Bostrom et al. (1991) - "Model it, let them experience it, discuss and process it, let them experience it again. Build in structured 'playtimes' - individual time for them to play with the technology" (p. 33). A group discussion on how and when to use the tools during an electronic meeting often followed this approach. Boud's (1993) notion that learners actively construct their own experience has been found to be a useful principle. This is because "experience is not a given; it is created by learners in relation to the learning milieu and their own personal foundation of experience. Different learners will have quite different experiences within the context of the same learning event" (p. 35). The trainees found that they had to construct their learning of GSS tools differently according to a meeting's context. For example, facilitating a meeting where conflict resolution is a high priority requires a different approach to the use of GSS tools than in a meeting where the participants conduct planning scenarios. Each trainee was encouraged to think about how these shared learnings could be incorporated into their individual facilitation style.

- Computer-supported group memory: At the beginning of each training session an electronic brainstorming tool was used to collect from the trainees' any issues that were important to them. We then looked at how these issues might influence how they learned to become electronic meeting facilitators. After each session the results were distributed and archived as the trainees' group memory. This method encourages the sharing of knowledge, skills and experience as resources for group members' learning.

- Mini-meetings: As well as learning the different GSS tools, the trainees were given the opportunity to integrate them into an electronic meeting. Each trainee demonstrated the use of the tools during 15 minute structured mini-meetings with their peers as participants in the meeting, and in each of the meetings the topic was a current interest of the facilitator-inpractice. Immediately after the session, self- and peer feedback comments on each trainee's performance was given (see next section).

It should be noted that these mini-meetings sessions were also used to increase the trainees' repertoire of facilitation skills and knowledge. The opportunity to
Table 3: The Relationship between Experiential Learning and the Training Programme

\begin{tabular}{|l|l|}
\hline Learning activity & Features from experiential learning \\
\hline Settling in & $\begin{array}{l}\text { Share their action and reflection with } \\
\text { others } \\
\text { Acknowledge that learning is an holistic } \\
\text { process which has affective and cognitive } \\
\text { features and occurs in a socio-emotional } \\
\text { context }\end{array}$ \\
\hline $\begin{array}{l}\text { Learning the GSS } \\
\text { tools }\end{array}$ & $\begin{array}{l}\text { Acknowledge the effects and influence of } \\
\text { prior experience on their learning }\end{array}$ \\
\hline $\begin{array}{l}\text { Computer-supported } \\
\text { group memory }\end{array}$ & $\begin{array}{l}\text { Use the knowledge, skills and experience } \\
\text { of other group members as resources for } \\
\text { their own learning }\end{array}$ \\
\hline $\begin{array}{l}\text { Mini-meetings } \\
\text { sessions }\end{array}$ & $\begin{array}{l}\text { Gain new experiences by taking risks in } \\
\text { testing new techniques and actions and } \\
\text { invite group members to provide feed- } \\
\text { back, taking that feedback and } \\
\text { implementing it, and reviewing with } \\
\text { those members the action taken and the } \\
\text { lessons that are learned }\end{array}$ \\
\hline $\begin{array}{l}\text { Self and peer feed- } \\
\text { back approach }\end{array}$ & $\begin{array}{l}\text { Share their action and reflection with } \\
\text { others }\end{array}$ \\
\hline $\begin{array}{l}\text { 'Wondering aloud' } \\
\text { moments }\end{array}$ & $\begin{array}{l}\text { Share their action and reflection with } \\
\text { others }\end{array}$ \\
\hline $\begin{array}{l}\text { 'Live' electronic } \\
\text { meeting }\end{array}$ & $\begin{array}{l}\text { Work and gather data on real issues and } \\
\text { problems associated with the facilitation } \\
\text { of electronic meetings }\end{array}$ \\
\hline
\end{tabular}

observe each other's experience during the practice sessions served as another source of learning. This approach is in agreement with Boud's (1993) principle that "learning occurs in a socio-emotional context. Learning rarely occurs effectively in social isolation. We teach in groups, we have face to face contact between teachers and students, students learn much with their peer groups and when these are absent, as in distance education, we commonly accept the need to provide additional support structures for students" (p. 36).

- $\quad$ Self- and peer feedback approach: To be of most use, high-quality feedback must follow the practice of a newlyacquired skill. Feedback comments often show us if we have got that skill right. More importantly, if suggestions for changes in behaviours are given in a supportive and helpful manner, then the potential to incorporate these changes will increase (see Appendix 1 for a full account). As explained in the previous section, these trainees were encouraged to use the self- and peer feedback approach after each practice session.

- 'Wondering aloud' moments: Another useful agenda item was the 'wondering aloud' moments. These were periods during the training sessions when trainees were encouraged to discuss with their peers their feelings, emotions, concerns, issues and reflections on what it was like to be a facilitator of electronic meetings. "Learning is an holistic process which has affective, cognitive and connotative fea- 
tures. We cannot pretend, as we often do in universities, that learning is purely a cognitive process.

Feelings and emotions are probably much more significant influences over what and how we learn than the ostensible cognitive content. The link with action is as necessary as it is ignored" (Boud 1993, p. 35).

\section{The 'Live' Electronic Meeting}

The practical module - 'Putting It All Together' - took place after the training. Trainees demonstrated the skills and knowledge acquired from the preceding training program by planning, managing and facilitating a 'live' electronic meeting which lasted about three hours. The participants in each meeting were told that, even though the meeting facilitator was undergoing training, they should use the meeting to deliberate on 'live' issues that were important to them. In other words, they were not in a 'mock' meeting. At the end of the meeting the meeting participants evaluated the trainee's performance. All the meetings were videotaped and the recordings used for giving feedback to the trainees and as research data for this study.

\section{The Relationship between Experiential Learning and the Training Programme}

The features of experiential learning methods have informed the design and implementation of the training program. Every effort has been made to link the features of experiential learning with the action and reflection activities in the program. The following table illustrates the relationship between a number of the learning activities and features of experiential learning:

\section{Summary}

What facilitators learned and how they are trained in the facilitation of electronic meetings will remain an important issue. From a research perspective, there is much to be done to understand this area of training of GSS facilitators. Avenues that require further research include the effectiveness of the experiential learning method, the importance of mentoring and coaching of trainee facilitators, the difference between training experienced and novice facilitators, and the training of facilitators of meetings held across time and place.

It is hoped that this paper, which describes an approach to the training of GSS facilitators, will promote identification of and discussion about the many complex issues associated with training. And more importantly, it is hoped that it will promote learning the craft of facilitating electronic meetings.

\section{References}

Anson, R. (1990). Effects of Computer Support and Facilitator Support on Group Processes and Outcomes: An
Experimental Assessment. Unpublished Doctoral Dissertation, Indiana University.

Anson, R., Bostrom, R. \& Wynne, B. (1995). An experiment assessing Group Support System and facilitator effects on meeting outcomes. Management Science. 41(2), 189-208.

Beranek, P., Beise, C. \& Niedermann, F. (1993). Facilitation and Group Support Systems. Proceedings of the Twenty-Sixth Annual Hawaii International Conference on Systems Sciences, 4, 199-207.

Bostrom, B., Clawson, V. \& Anson, R. (1991). Training people to facilitate electronic environments. Working Paper, Dept. of Management, University of Georgia.

Bostrom, R., Anson, R., \& Clawson, V. (1993). Group facilitation and Group Support Systems in Jessup, L. and Valacich, J. (eds.), Group Support Systems, (pp. 146-168). Macmillan.

Boud, D. (1993). Experience as a base for learning. Higher education research and development, 12(1), 33-44.

Center for the Enhancement of Teaching. (1997). Active, Cooperative, and Experiential Learning. University of Northern Iowa. (On-line), http://iscssun.uni.edu/teachctr/active.html

Clawson, V. (1992). The Role of the Facilitator in ComputerSupported Environments. Unpublished Doctoral Dissertation, Walden University.

George, J., Dennis, A., \& Nunamaker, J. (1992). An Experimental Investigation of Facilitation in an EMS Decision Room, Group Decision and Negotiations, 1, 57-70.

Heron, J. (1981). Self and peer assessment, in Boydell, T. and Pedlar, M. (eds.), Handbook of management self-development. Gower, London.

Hirokawa, R. \& Gouran, D. (1989). Facilitation of Group Communication: A Critique of Prior Research and an Agenda for Future Research, Management Communication Quarterly, 3(1), 71-92.

Iacono, S., Vogel, D., \& Nunamaker, J. (1990). GroupSystems Facilitation, Working Paper, Department of MIS, University of Arizona.

Kelly, G. \& Bostrom, R. (1995). Facilitating the socio-emotional dimensions in group support systems. Proceedings of the ACM SIGCPR 1995 Conference, Nashville, Tennessee. 10-23.

Kolb, D.A. (1984). Experiential learning: Experience as the source of learning and development. Prentice-Hall, Englewood Cliffs, N. J. 
GSS facilitation training

McGoff, C.J. \& Ambrose, L. (1991). Empirical information from the field: A practitioner's view of using GDSS in business. Proceedings of the Twenty-Fourth Annual Hawaii International Conference on Systems Sciences.

Perreault, H. (1993) Training is the key to implementing a group decision support system. Journal of Information Systems Education, 5(1). (http://www.gise.org/JISE/Vol15/TRAINING.htm)

Ventana (1996). Learn It Fast and Learn It Right, GroupSystems@Work January.

Vogel, D., Nunamaker, J., Applegate, L., \& Konsynski, B. (1987). Group Decision Support Systems: determinants of success. Proceedings of the Seventh International Conference on Decision Support Systems, 118-128.

Yoong, P. (1995). Assessing competency in GSS skills: A pilot study in the certification of GSS facilitators. Proceedings of the ACM SIGCPR 1995 Conference, Nashville, Tennessee, 1-9.

Yoong, P. (1996). A Grounded Theory of Reflective Facilitation: Making The Transition From Traditional To GSS Facilitation. Unpublished doctoral thesis, Victoria University of Wellington, New Zealand.

\section{Appendix 1 Observations and Feedback Approach}

The following 'self and peer assessment' approach is adapted from Heron (1981).

During this feedback process, there are three major roles: (a) the Facilitator, (b) the Feedback-Facilitator and (c) the Observers.

Role of the Facilitator: In this feedback process, your role is that of a demonstrator and your goal is to demonstrate the "facilitative" behaviours that you want feedback on.

Role of the Feedback-Facilitator: You are the guardian of the feedback process. You will ensure that: (a) the ground rules are followed, (b) each step in the process is satisfactorily completed before the next step is commenced, and (c) the integrity and dignity of the facilitator is protected.

Role of the Observers: Your role is to observe the specified behaviours given in step 2 below and to provide high quality feedback to the Facilitator.

1. Facilitator will select the Feedback-Facilitator and the two observers for the feedback round. (The other participants are observers and co-learners who do not offer feedback).

2. Facilitator lists up to three facilitative behaviours requiring observations and feedback.
3. Facilitator demonstrates those behaviours and observers note comments (both negative and positive) on paper.

4. Feedback-Facilitator reminds observers about the ground rules and clarifies, if necessary.

5. Feedback-Facilitator invites the Facilitator to give (self) negative feedback and suggestions for change.

6. Feedback-Facilitator invites the observers to give negative feedback (say, at most, two comments) and suggestions for change. A minute's silence is observed to give the facilitator time to sift the relevant information.

7. Feedback-Facilitator invites the Facilitator to give positive feedback.

8. Feedback-Facilitator invites the observers to give positive feedback.

A minute's silence is observed to give the facilitator time to sift the relevant information.

9. Feedback-Facilitator reminds participants about the need to cease discussion unless it has the "OK" of the Facilitator.

10. Celebrations. 